\title{
The Teleconnection between the Western Indian and the Western Pacific Oceans
}

\author{
Vasubandhu Misra \\ Center for Ocean-Land-Atmosphere Studies \\ Institute of Global Environment and Society, Inc. \\ 4041 Powder Mill Road, Suite 302 \\ Calverton, MD 20705. \\ E-mail: misra@cola.iges.org
}

November 2002 


\begin{abstract}
In this study we show a teleconnection pattern relating Outgoing Longwave Radiation (OLR) anomalies over the western Pacific Ocean and sea surface temperature anomalies (SSTA) over the western Indian Ocean over two seasons (Sept-Oct-Nov and Dec-Jan-Feb) at zero lag from observations and atmospheric general circulation model (AGCM) integrations. This teleconnection pattern suggests that a positive SSTA in Sept-Oct-Nov (SON) and Dec-Jan-Feb (DJF) seasons over the western Indian Ocean increases the contemporaneous positive OLR anomalies over the western Pacific Ocean. This teleconnection pattern is also simulated by the Center for Ocean-LandAtmosphere studies (COLA) AGCM forced with observed SST's. From the experimental COLA AGCM runs (wherein the Pacific Ocean SST variability is suppressed except for the climatological annual cycle) it is diagnosed that the interannual variability of OLR over the western Pacific Ocean persists because of this teleconnection. In relation to this teleconnection pattern it is shown that there is a significant linear response of the SON and DJF equatorial zonal wind anomaly over the Pacific Ocean to contemporaneous SSTA over the western Indian Ocean which is comparable to that of the eastern and western Pacific Oceans. The experimental AGCM runs clearly show that this response of the equatorial zonal wind anomaly to the western Indian Ocean forcing shifts westward towards the Indian Ocean in the absence of Pacific SST variability.
\end{abstract}




\section{Introduction}

In this study we explore the relationship between the western Indian Ocean (WIO) sea surface temperature (SST) variability and Outgoing Longwave Radiation (OLR) variability on interannual time scales over the western Pacific Ocean (WPO) from both atmospheric general circulation model (AGCM) integrations and observations. In the recent past, the relation between the variability of the SST over the Indian Ocean and climate variation elsewhere has been extensively investigated. The influence of the Indian ocean SST anomalies (SSTA) on the Indian monsoon has been documented in Shukla (1987), Clark et al. 2000 and Arpe et al. (1981). Meehl (1993, 1987) indicated that both the Indian and Pacific Oceans were actively involved in the evolution of El Niño through the modulation of the tropical biennial oscillation. Similarly, Nicholls (1989), Makaru and Jury (1997) and Latif et al. (1999) have identified the role of Indian Ocean SSTA on climate variability over Australia, Zimbabwe and and eastern equatorial Africa respectively.

There are a number of studies which show that Indian Ocean SST is influenced by SSTA in the eastern Pacific at a lag of a few months (Klien et al. 1999; Venzke et al., 2000; Nicholson, 1997). Klien et al. (1999) show that variablity in clouds, surface winds and thereby the surface fluxes over the Indian Ocean correspond with SST variability over the Pacific Ocean. Krishnamurti and Kirtman (2001) indicate that the dipole like variation in the Indian Ocean SST is largely a manifestation of the El Niño and Southern Oscillation (ENSO) phenonmenon, but that it can be excited by processes that are independent of ENSO. Huang and Kinter (2002) show that there is variability in the time period of $2-5$ years in the sub-surface tropical Indian Ocean which is significantly correlated to ENSO variability.

Some recent studies have however, also shown that variability of the Indian Ocean may have influence on the variability of the Pacific Ocean. Meehl et al. (1999) show that the subseasonal propogation of convection from the Indian Ocean to western Pacific utlimately culminates with 
westerly wind burst events over the western Pacific which serve as a prelude to an evolving ENSO. Curtis et al. (2002) using observations and National Centers for Environmental Prediction (NCEP) reanalysis identified an eastern equatorial Indian Ocean (EEIO) mode of variability with a periodicity of 2-7 years. This mode is depicted as a precipitation gradient south of Sumatra island and the central equatorial Indian Ocean. They show that in the 3-4 months following the positive phase of this EEIO mode (with enhanced rainfall over south of Sumatra) there is a surge in the power of 30-60 day oscillation over the region which has a significant correlation with ENSO events.

The results of this study must be viewed with a caveat because we have not made an attempt to explain the that the appearance of the SSTA over WIO. This study proceeds to explain the teleconnection pattern once siginificant SSTAs establish in the WIO which happens to be in SeptOct-Nov (SON) season (Krishnamurthy and Kirtman, 2001). Therefore, we do not discount the scenarios depicted by the studies referenced above. We subscribe to the idea that there is a synergestic relationship between the Indian and Pacific Oceans and the variability in the two ocean basins are equally important to the ultimate evolution of ENSO and ENSO like variability in the Pacific Ocean.

In the following section we list the outline of the AGCM used in the study followed by a description of the design of experiments and datasets used. The interannual variability of the OLR anomaly over WPO is discussed in section 3a. Subsequently we describe the teleconnection pattern in section $3 \mathrm{~b}$ and provide an explanation for it from the model simulations and observations in section 3c. We finally present our conclusions in section 4.

\section{Design of experiments and datasets}

For this study, we ran 6 ensemble members of the control COLA AGCM at T42 spectral truncation with 18 levels for 18 years starting from December 15, 0000UTC, 1978. The details of the model are outlined in Table 1. The atmospheric initial conditions for these ensemble mem- 
bers were generated by initially running the COLA AGCM from NCEP reanalysis for December 15, 0000UTC, 1978 for a week and resetting the date on the restart file to the initial date. This procedure was repeated five more times to obtain synoptically independent atmospheric initial conditions for the other ensemble members. This procedure has been adopted in other past studies (Misra et. al., 2002; Kirtman et al. 2001). The surface boundary condition of SST is obtained from the monthly mean of Hadley center Sea-Ice and Sea Surface Temperature (HADISST) data set (Parker et al., 1991). This dataset is available on a $1^{\circ} \times 1^{\circ}$ grid from 1870 to present. The soil moisture fields are obtained from a 2 year climatology of the global soil wetness project (Dirmeyer and Zeng, 1999).

A set of 6 additional experimental model runs were conducted using the same initial atmospheric and land surface conditions as in the control COLA AGCM as above. However in these experimental runs seasonally varying climatological SST was used over the entire Pacific Ocean while in the rest of the ocean basins the observed SST was used. The purpose of these experiments is to identify the mechanism of the remote forcing of WPO rainfall.

To verify some of the results from these model simulations we use the NCEP reanalysis (Kalnay et al. 1996). The model Outgoing Longwave Radiation (OLR) is validated against the observed OLR which follows Liebmann and Smith (1996) and is obtained as the interpolated OLR data set from the NOAA-CIRES Climate Diagnostics Center, Boulder, Colorado. This dataset is available on $2.5^{\circ} \times 2.5^{\circ}$ lat-lon grid. It should be mentioned that all results from the model simulation in this study are use the ensemble mean.

\section{Results}

\section{3a Interannual Variability of Western Pacific OLR anomalies}

The COLA AGCM has been extensively used for climate simulations (Misra, 2002; Straus and Shukla, 2002). It has also been successfully coupled to an ocean model which reproduces 
the present climate reasonably well (Kirtman et al, 2002). In this section we compare the WPO OLR anomalies from the control and experiment AGCM integrations with observations. The intent is to document the reliability of the COLA AGCM in simulating the tropical variability. In Fig. 1a we show the longitude time cross-section of OLR anomalies averaged between $10 \mathrm{~S}$ and $10 \mathrm{~N}$ and the corresponding observations in Fig. 1b. The interannual variability over tropical Pacific is reasonably well captured by the model. The warm (cold) ENSO events of 1983-84, 1987-88, 1991-92 (1984-85, 1985-86, 1996-97) with negative (positive) OLR anomalies from Fig. 1a are verifiable in Fig. 1b. However, in the control model integrations the positive OLR anomalies extend too far to the east and the high frequency variability is relatively dormant.

The motivation for this study primarily came from Fig. 2 which shows the time series of the OLR anomalies over WPO (domain shown in Table 2) from control, observations and experimental run. It is clearly seen that the experimental model also exhibits an interannual variability over WPO, albeit with a much smaller magnitude than in the control and observations despite specifying only climatological annual cycle of SST over the Pacific Ocean. The goal of this study is to understand the cause of this variability over WPO. It is also seen Fig. 2a that the control model cleary does not simulate the observed high frequency variability of OLR over the WPO.

\section{3b The Teleconnection Pattern}

Krishnamurthy and Kirtman (2001) indicated that there is a lag of about one season in the interannual variability of the monthly mean SSTA between WIO and WPO. Specifically, they indicated that peak variability in SSTA occur in Sep-Oct-Nov (SON) over WIO followed by peak variability in Dec-Jan-Feb (DJF) over WPO. Furthermore, we found that the largest interannual anomalies of rainfall over WPO from AGCM control simulations and observations appears in DJF which are also comparable to SON anomalies in some years (not shown). We were therefore motivated to examine the contemporaneous correlations of rainfall variability over WPO with global SSTA for 
SON and DJF.

In Figs. $3 \mathrm{a}$ and $\mathrm{b}$ we show the contemporaneous correlation significant at $90 \%$ confidence interval according to two-tailed t-test between the WPO OLR anomalies and global SST for SON and DJF seasons from the control COLA AGCM simulations respectively. The teleconnection appears strongest in SON over WIO which spreads further eastward in DJF over the eastern Indian Ocean. These teleconnection patterns were further explored from observations in Fig. 4. The observations seem to verify the AGCM simulations with the teleconnection appearing over WIO in SON and spreading further eastward in DJF. However, there are significant differences between the control and observed teleconnection patterns. The foremost of these is the appearance of relatively much stronger correlations over WIO in the control in Fig. 3a relative to observations in Fig. 4a. In addition, the display of strong local forcing over WPO in SON and DJF, and a relatively stronger reponse to SSTA over the Eastern Pacific Ocean (EPO) in Fig. 3 relative to observations in Fig. 4 are some of the glaring deficiencies of the control COLA AGCM simulation. Notwithstanding these errors in the AGCM, we can still glean some useful information from it.

A similar correlation plot was also made for the experimental AGCM runs which are shown in Fig. 5. Here we see that that the teleconnection pattern over WIO persists in both SON and DJF seasons. However, it does not spread eastward over eastern Indian Ocean in DJF unlike the control simulation. The experimental runs therefore indicate that the Pacific SST variability interferes with the seasonal variation of this teleconnection pattern. It should be mentioned that such a clean comparison of the teleconnections with and without Pacific SST variability is not possible with observations. Furthermore, the weak ENSO events between 1979 to 1997 are not adequate to produce a statistically significant result for weak ENSO events as is possible from the model sensitivity experiments.

The correlations over tropical Atlantic which appear in Fig. 5b are significant but unobserved. 
Huang et. al (2001) in their study found that remote forcing of ENSO from the Pacific Ocean enhances and modulates the Atlantic SST variability. They further showed that El Niño induced perturbations in the Atlantic Ocean cause stronger cross-equatorial flow, weaker northeast trades and warmer SST over the northern basin of the tropical Atlantic from boreal winter to spring seasons. Czaja et al.(2002) attribute all strong anomalies in the north Tropical Atlantic SST from 1950 to present to prior ENSO and North Atlantic Oscillation (NAO) events. They show that NAO and ENSO influence the evaporation over the north tropical Atlantic by influencing the subtropical high pressure system and the related trade winds.

\section{3c Regression Analysis}

In this section we shall try to explain this teleconnection pattern from the observations and the COLA AGCM simulations. Our working hypothesis for this teleconnection pattern is that the WIO SST is connected to the WPO OLR anomalies (a proxy to divergent circulations) through the east west atmospheric equatorial circulation which is modulated by the underlying SST. To establish this hypothesis we have plotted in Fig. 6a, b and c the vertical cross-section of the contemporaneous response of the equatorial zonal wind (EZW) anomaly obtained by a linear regression analysis on SSTA for DJF over the WIO, the EPO and the WPO respectively. The EZW climatology for DJF is shown in Fig. 6d. The domains of WIO, EPO and WPO are indicated in Table 2. It should be noted that in these figures, the response of the EZW is calculated for the respective standard deviations of SST over the WIO, the EPO and the WPO (listed in Table 2). Despite the fact that the standard deviation of SST over the WIO is much smaller than that over the EPO and more remotely located from the WPO, the response of the EZW over WPO in Fig. 6a is comparable in magnitude to that in Figs. $6 \mathrm{~b}$ and $\mathrm{c}$. Furthermore, it is seen that a postive SSTA over the WIO weakens the lower (upper) level westerlies (easterlies) over the WPO and likewise weakens the lower (upper) level easterlies (westerlies) over the EPO. This response is similar but with slightly 
larger magnitude to positive SSTA over the EPO as shown in Fig. 6b. However the response of the EZW to positive SSTA over the WPO is opposite in nature viz., it acts to enhance the east west circulation over the the Pacific Ocean. It should be noted that a similar relationship also appears in SON season (not shown).

The response patterns of EZW are verified using NCEP reanalysis winds for DJF season over the same time period (Jan. 1979- Dec. 1997) as the model integration period in Fig. 7. It is seen that the sign of the response of the EZW in these figures agrees with the model results reasonably well. However, it should be mentioned that the response of EZW over the eastern Indian Ocean both at lower and upper levels to underlying SSTA over WIO, WPO and EPO is much stronger in the NCEP reanalysis than in the control AGCM simulation. The SON seasonal response of NCEP reanalysis EZW (not shown) was similar to the DJF response.

In Figs. 8a we display the response of the EZW from the experimental run to SSTA over WIO for DJF. The seasonal climatology is shown in Fig. 8b. It is seen that relative to the control simulations the response of the EZW over the Pacific Ocean to SSTA over the WIO has significantly reduced while its influence on EZW over the Indian Ocean has increased. This is consistent with the study of Misra (2002) who showed that that there is a global shift of the divergent circulations with the rising cell of the Walker circulation moving westward towards the eastern Indian Ocean in the absence of Pacific SST variability. Therefore it may be concluded from this analysis that the interannual variability of precipitation over the WPO seen in the experimental run (in Fig. 2) is a result of the modulation of EZW by the SSTA over the WIO which impact, the divergent circulations over the WPO.

\section{Conclusions}

In this study we have shown that the western Indian Ocean (WIO) SST variability plays a critical role in the variability of the OLR anomaly over western Pacific Ocean (WPO) at least 
over two seaons of SON and DJF. We have used both AGCM simulations and observations to verify this relationship. The WPO OLR anomalies correlate positively with WIO SSTA in these teleconnection patterns in SON and DJF. In the absence of ENSO variability the correlation over the WIO is further strengthened in SON and DJF seasons in the model integrations. A regression analysis was performed to understand this teleconnection pattern both in observations and model integrations. There is a comparable response in SON and DJF of the EZW to contemporaneous SSTA over the WIO relative to SSTA over WPO and EPO. This conditioning of the EZW by the WIO plays a very significant role in the variabilty over the WPO as determined from the teleconnection pattern. In the absence of ENSO variability in the Pacific SST, the response of the EZW over the Pacific (Indian) Ocean to SSTA over the WIO diminishes (increases) appreciably. This enhances the teleconnection pattern between the WPO OLR anomalies and the WIO SST variability.

\section{Acknowledgements}

We would like to thank Paul Dirmeyer for providing the SST datasets for the experimental run and Ben Kirtman for their encouragement to pursue this study. This project was supported by NASA grant NAG5-8416 and NOAA grant NA86GP0258. 


\section{References}

Arpe, K., L. Dumenil and M. A. Giorgetta, 1998: Variability in the Indian Monsoon in the ECHAM3 model: Sensitivity to sea surface temperature, soil moisture, and the stratospheric quasi-biennial oscillation. J. Climate, 11, 1837-1858.

Clark, C. O., J. E. Cole, and P. J. Webster, 2000: Indian Ocean SST and Indian Summer Rainfall: Predictive relationships and their decadal variability. J. Climate, 13, 2503-2519.

Czaja, A., P. Van Der Vaart and J. Marshall, 2002: A Diagnostic Study of the Role of Remote Forcing in Tropical Atlantic Variability. J. Climate, 15, 3280-3290.

Curtis, S., G. J. Huffman and R. F. Adler, 2002: Precipitation anomalies in the tropical Indian Ocean and their relation to the initiation of El Niño. Geophys. Res. Let., 29, 83-1-83-4.

Davies, R., 1982: Documentation of the solar radiation parameterization in the GLAS climate model. NASA Technical memorandum, 83961, 57 pp.

Dirmeyer, P. A., and F. J. Zeng 1999: Precipitation infiltration in the Simplified SiB land surface scheme. J. Meteor. Soc. Japan, 78, 291-303.

Fennessy, M. J., J. L. Kinter III, B. Kirtman, L. Marx, S. Nigam, E. K. Schneider, J. Shukla, D. Straus, A. Vernekar, Y. Xue and J. Zhou, 1994: The Simulated Indian monsoon: A GCM Sensitivity Study, J. Climate, 7, 33-43.

Gates, W. L. and others, 1998: An overview of the results of the Atmospheric Model Intercomparison Project (AMIP1). Bull. Amer. Soc., 73, 1962-1970.

Harshvardhan, R., R. Davies, D. A. Randall and T. G. Corsetti, 1987: A fast radiation parameterization for atmospheric circulation models. J. Geophy. Res., 92(D1), 1009-1016.

Huang, B. and J. L. Kinter, 2002: Interannual variability in the tropical Indian Ocean. J. Geophy. Res.. In press.

Huang, B., P. S. Schopf and Z. Pan, 2002: The ENSO effect on the tropical Atlantic Variability: A regionally coupled model study. Geophys. Res. Let.. In press.

Kalnay and others, 1996: The NCEP/NCAR 40-year Reanalysis Project. Bull. Amer. Soc., 77, 431-437. 
Kiehl, J. T., J. J. Hack, G. Bonan, B. A. Boville, D. L. Williamson and P. J. Rasch, 1998: The National Center for Atmospheric Research Community Climate Model: CCM3. J. Climate, 11, 1131-1149.

Kirtman,B. P., D. A. Paolino, J. L. Kinter and D. M. Straus, 2001: Impact of tropical subseasonal SST variability on seasonal mean climate simulations. Mon. Wea. Rev., 129, 853-868.

Kirtman,B. P., Y. Fan and E. K. Schneider, 2002: The COLA global coupled and anomaly coupled ocean-atmosphere GCM. J. Climate, 15, 2301-2320.

Klien, S. A., B. J. Soden, and N. C. Lau, 1999: Remote sea surface temperature variations during ENSO: Evidence for a tropical atmospheric bridge. J. Climate, 12, 917-932.

Krishnamurthy and B. P. Kirtman, 2001: Variability of the Indian Ocean: Relation to Monsoon and ENSO. COLA Rep. 107, 39pp. [Available from COLA, 4041 Powder Mill Rd., Suite 302, Calverton, MD 20705.]

Lacis, A. A., and J. Hansen, 1974: A parameterization for the absorption of solar radiation in the earth's atmosphere. J. Atmos. Sci., 31, 118-133.

Latif, M., D. Dommenget, M. Dima, and A. Grotzner, 1999: The role of Indian Ocean sea surface temperature in forcing east African rainfall anomalies during December-January 1997/98. J. Climate, 12, 3497-3504.

Liebmann, B. and C. A. Smith, 1996: Description of a complete (interpolated) outgoing longwave radiation dataset. Bull. Am. Soc., 77, 1275-1277.

Makarau, A. and M. R. Jury, 1997: Predictability of Zimbabwe summer rainfall. Int. J. Climatol., 17, 1421-1432.

Meehl, G. A., 1993: A coupled air-sea biennial mechanism in the tropical Indian and Pacific Ocean regions. J. Climate, 6, 31-41.

Meehl, G. A., 1987: The annual cycle and interannual variability in the tropical Indian and Pacific Ocean regions. Mon. Wea. Rev., 115, 27-50.

Meehl, G. A., G. N. Kiladis, K. M. Weickmann, M. Wheeler, D. S. Gutzler and G. P. Compo, 
1996: Modulation of equatorial subseasonal convective episodes by tropical-extratropical interaction in the Indian and Pacific Ocean regions. J. Geophys. Res., 101, 15,03315,049 .

Mellor, G. L. and T. Yamada, 1982: Development of a turbulence closure model for geophysical fluid processes. Rev. Geophys. Space Phys., 20, 851-875.

Misra, V., 2002: The influence of Pacific SST variability on the precipitation over Southern Africa. Accepted in J. Climate.

Moorthi, S. and M. J. Suarez, 1992: Relaxed Arakawa-Schubert: A parameterization of moist convection for general circulation models. Mon. Wea. Rev., 120, 978-1002.

Nicholls, N. 1989: Sea surface temperatures and Australian winter rainfall. J. Climate, 2, 965973.

Nicholson, S. E., 1997: An analysis of the ENSO signal in the tropical Atlantic and western Indian Oceans. Int. J. Climatol., 17, 345-375.

Parker, D. E., N. A. Rayner, E. B. Horton and C. K. Folland, 1999: Development of the Hadley Center sea ice and sea surface temperature data sets (HADISST). WMO workshop on Advances in Marine Climatology-CLIMAR99, 194-203. [Available from Environment Canada, Ontario].

Shukla, J., 1987: Interannual variability of monsoons, in Monsoons, edited by J. S. Fein and P. L. Stephens, pp 399-463, John Wiley, New York.

Straus, D. and J. Shukla, 2002: Does ENSO force the PNA? J. Climate, 15 , 2340-2358.

Tiedtke, M., 1984: The effect of penetrative cumulus convection on the large-scale flow in a general circulation model. Beitr. Phys. Atmos., 57, 216-239.

Venzke, S., M. Latif, and A. Villwock, 2000: The couple GCM ECHO-2.2 Indian Ocean response to ENSO. J. Climate, 13, 1371-1383.

Xue, Y-K., P. J. Sellers, J. L. Kinter and J. Shukla, 1991: A simplified Biosphere Model for global Climate Studies. J. Climate, 4, 345-364.

Xue, Y-K., F. J. Zeng and C. A. Schlosser, 1996: SSiB and its sensitivity to soil properties. A 
case study using HAPEX-Mobilhy data. Global and Planetary Change, 13, 183-194. 


\begin{tabular}{|l|l|}
\hline Process & Reference \\
\hline Dynamical Core & Kiehl et al. (1998) \\
\hline Advection & $\begin{array}{l}\text { Dependent variables are spectrally treated } \\
\text { except for moisture variable which is } \\
\text { adevected by semi-lagrangian scheme. }\end{array}$ \\
\hline Time integration & Semi-implicit \\
\hline Deep convection & $\begin{array}{l}\text { Relaxed Arakawa Schubert scheme, } \\
\text { Moorthi and Suarez (1992) }\end{array}$ \\
\hline Shallow convection & Tiedke (1984) \\
\hline Shortwave radiation & Davies (1982) \\
\hline Longwave radiation & Harshvardhan et al. (1987) \\
\hline Boundary layer & $\begin{array}{l}\text { level 2.0 closure, } \\
\text { Mellor and Yamada (1982) }\end{array}$ \\
\hline $\begin{array}{l}\text { Diagnostic cloud fraction } \\
\text { and optical properties }\end{array}$ & Kiehl et al. (1998) \\
\hline Orography & Smoothed mean (Fennessy et al., 1994) \\
\hline Land surface process & Xue et al. (1991, 1996) \\
\hline
\end{tabular}

Table 1: The outline of the AGCM used in the study. 


\begin{tabular}{|l|l|l|l|}
\hline Area & Domain & $\sigma$ for SON & $\sigma$ for DJF \\
\hline Western Indian Ocean (WIO) & $50^{\circ} \mathrm{E}-70^{\circ} \mathrm{E}$ and & & \\
& $10^{\circ} \mathrm{S}-10^{\circ} \mathrm{N}$ & 0.233 & 0.208 \\
\hline Eastern Pacific Ocean (EPO) & $110^{\circ} \mathrm{W}-85^{\circ} \mathrm{W}$ and & & \\
& $5^{\circ} \mathrm{S}-5^{\circ} \mathrm{N}$ & 1.107 & 0.827 \\
\hline Western Pacific Ocean (WPO) & $\begin{array}{l}150^{\circ} \mathrm{E}-160^{\circ} \mathrm{E} \text { and } \\
\\
10^{\circ} \mathrm{S}-10^{\circ} \mathrm{N}\end{array}$ & 0.239 & 0.318 \\
\hline
\end{tabular}

Table 2: The domains of the oceanic regions used in the regression analysis and their standard deviation $(\sigma)$ in $\mathbf{C}$. 

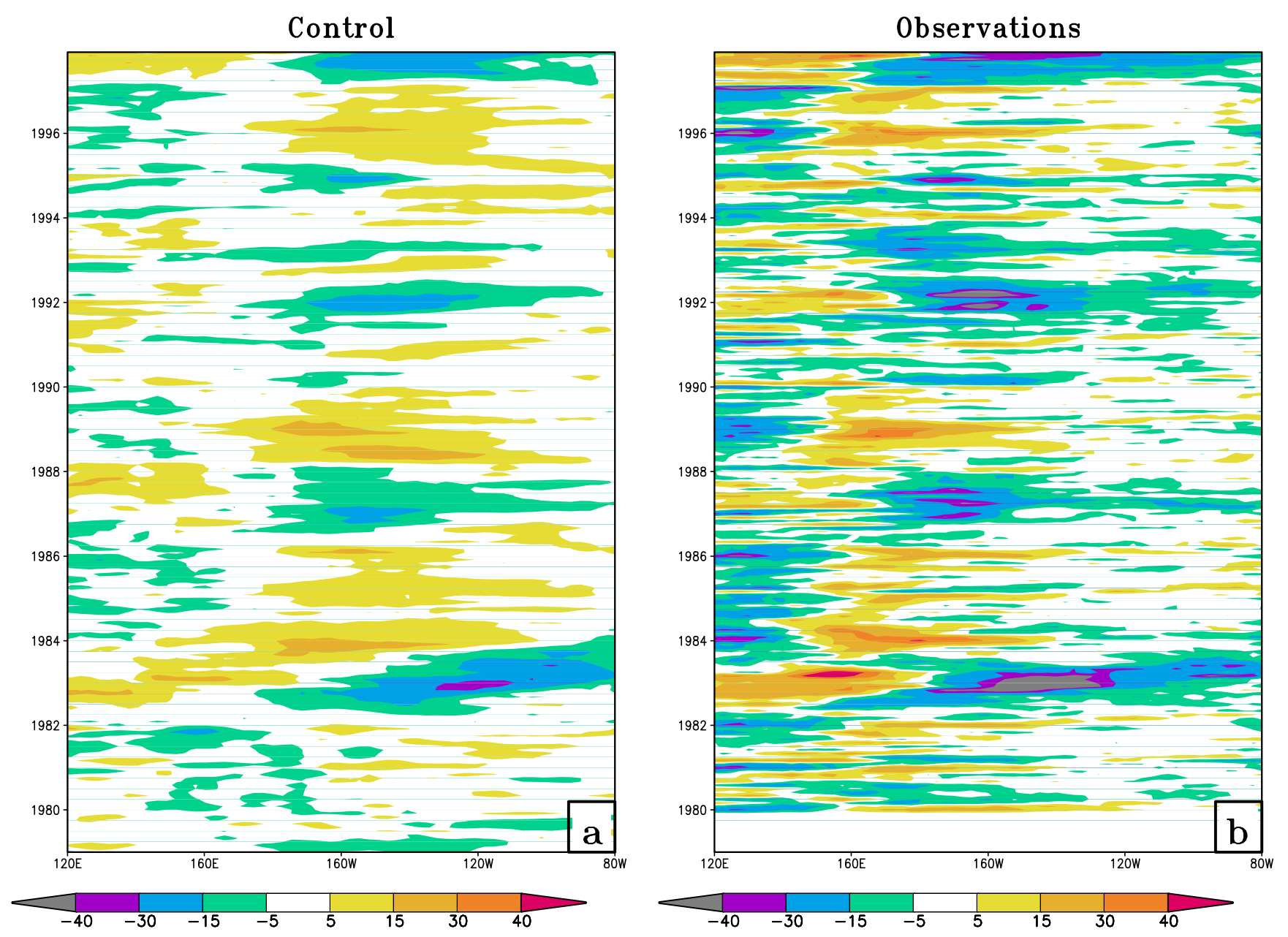

Figure 1: The OLR anomalies averaged between $10 \mathrm{~S}$ and $10 \mathrm{~N}$ from a) control COLA AGCM and b) Obervations based on Liebmann and Smith (1996). The units are in $\mathrm{Wm}^{-2}$. 

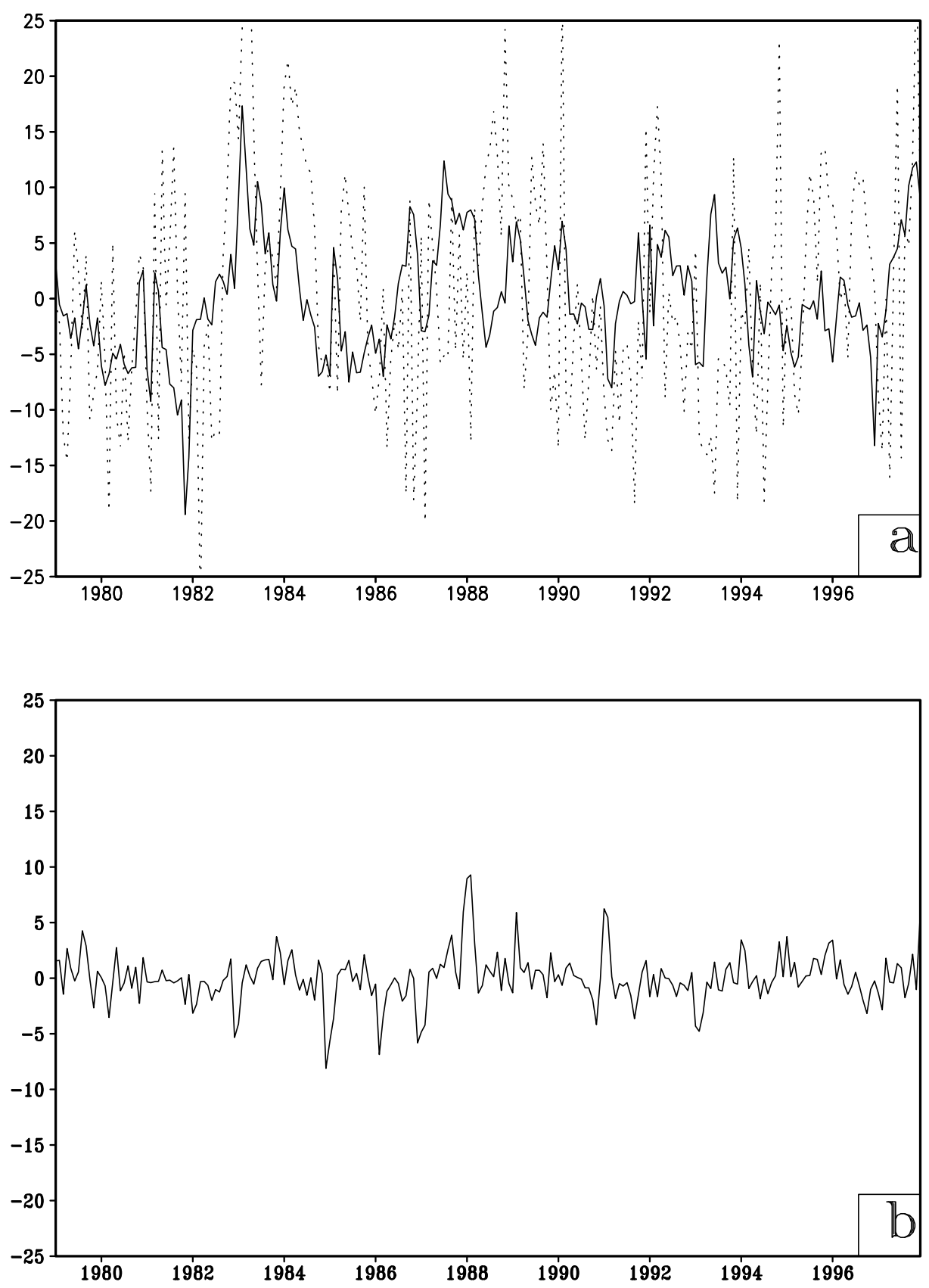

Figure 2: The time series of OLR anomalies averaged over western Pacific Ocean (see Table 2) from a) Control (solid line) and observations (dotted line) and b) Experimental COLA AGCM simulations. The units are in $\mathrm{Wm}^{-2}$. 

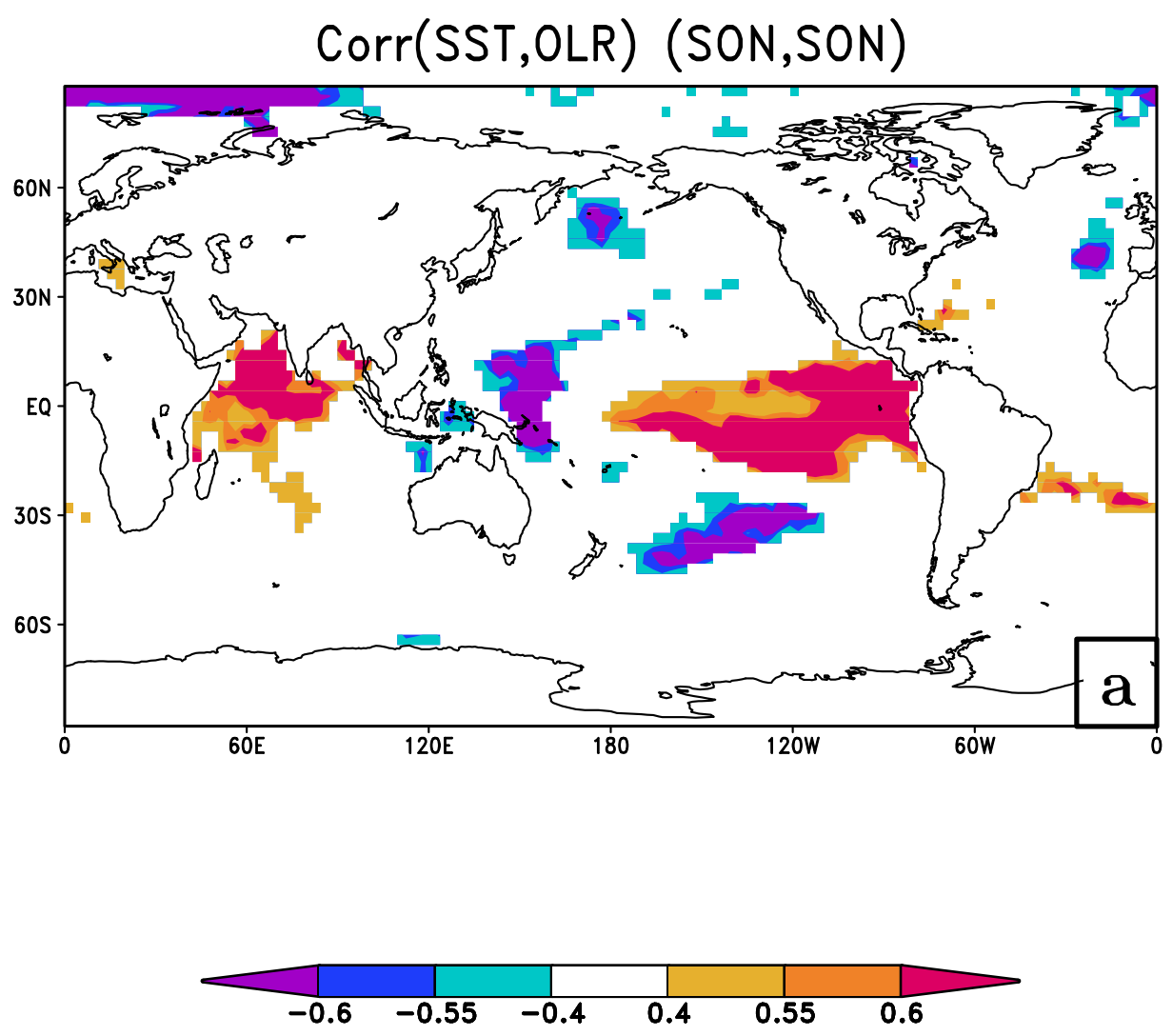

Corr(SST,OLR) (DJF,DJF)

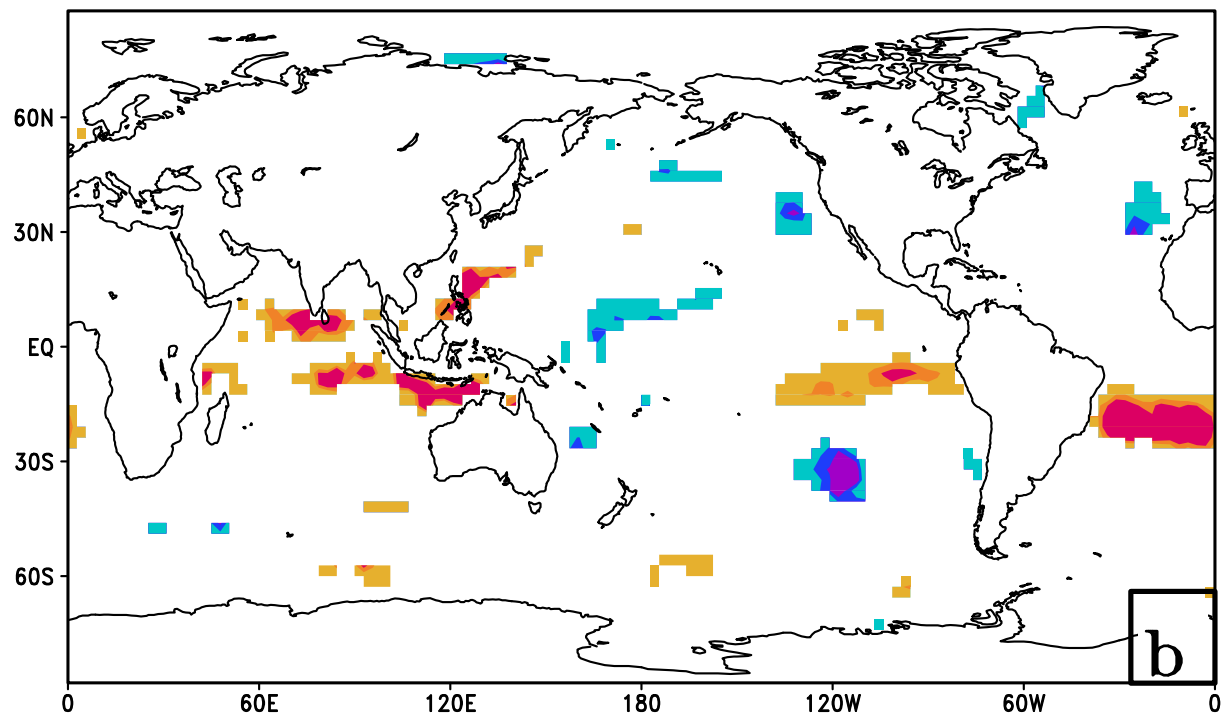

Figure 3: The contemporaneous correlation of western Pacific OLR anomalies with global SST for a) SON and b) DJF from control AGCM simulations. Only significant values at $90 \%$ confidence interval according to t-test are plotted. 

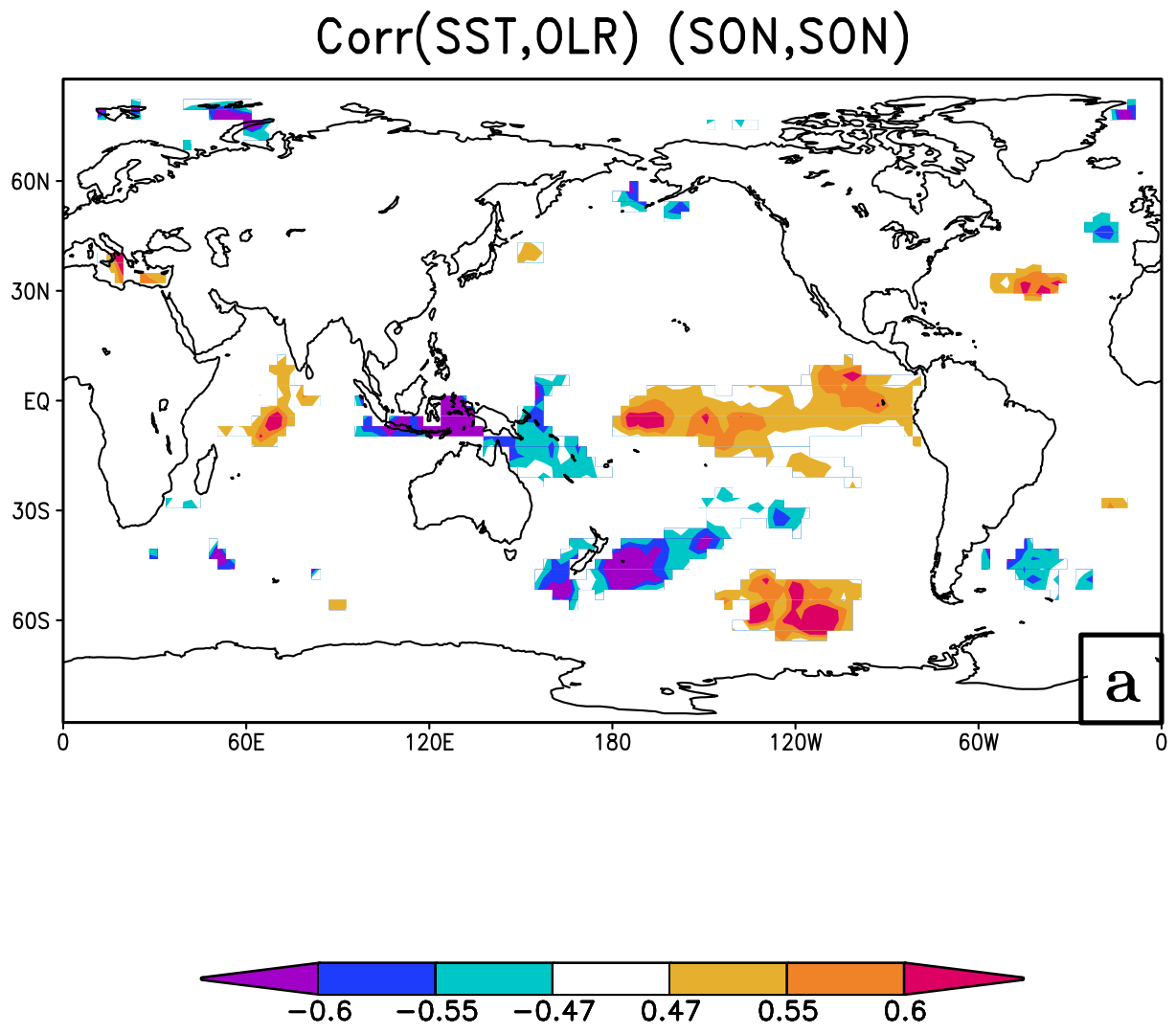

Corr(SST,OLR) (DJF,DJF)
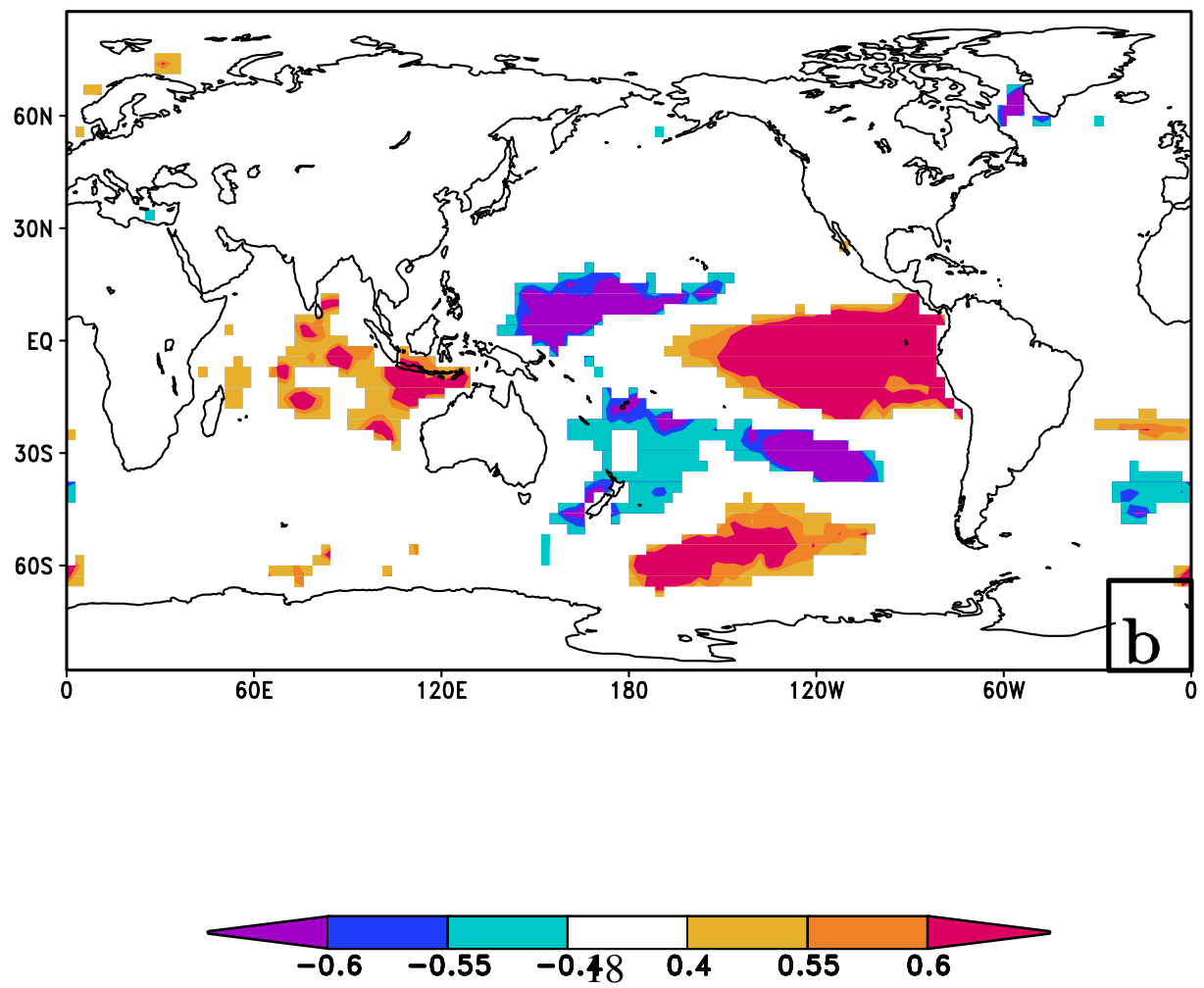

Figure 4: Same as Fig. 3 but from observations. 

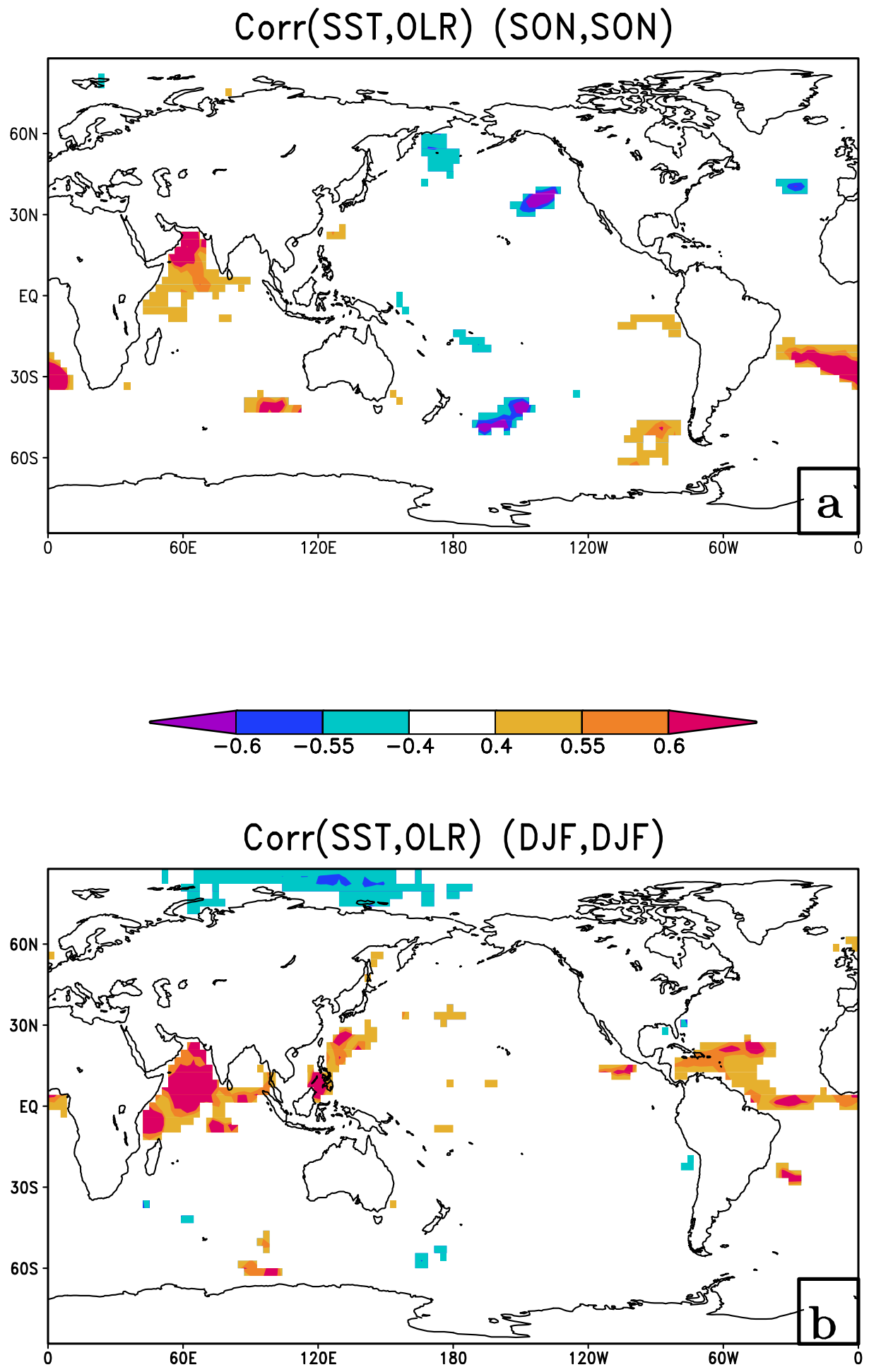

Figure 5: Same as Fig. 3 but from experimental AGCM simulations. 

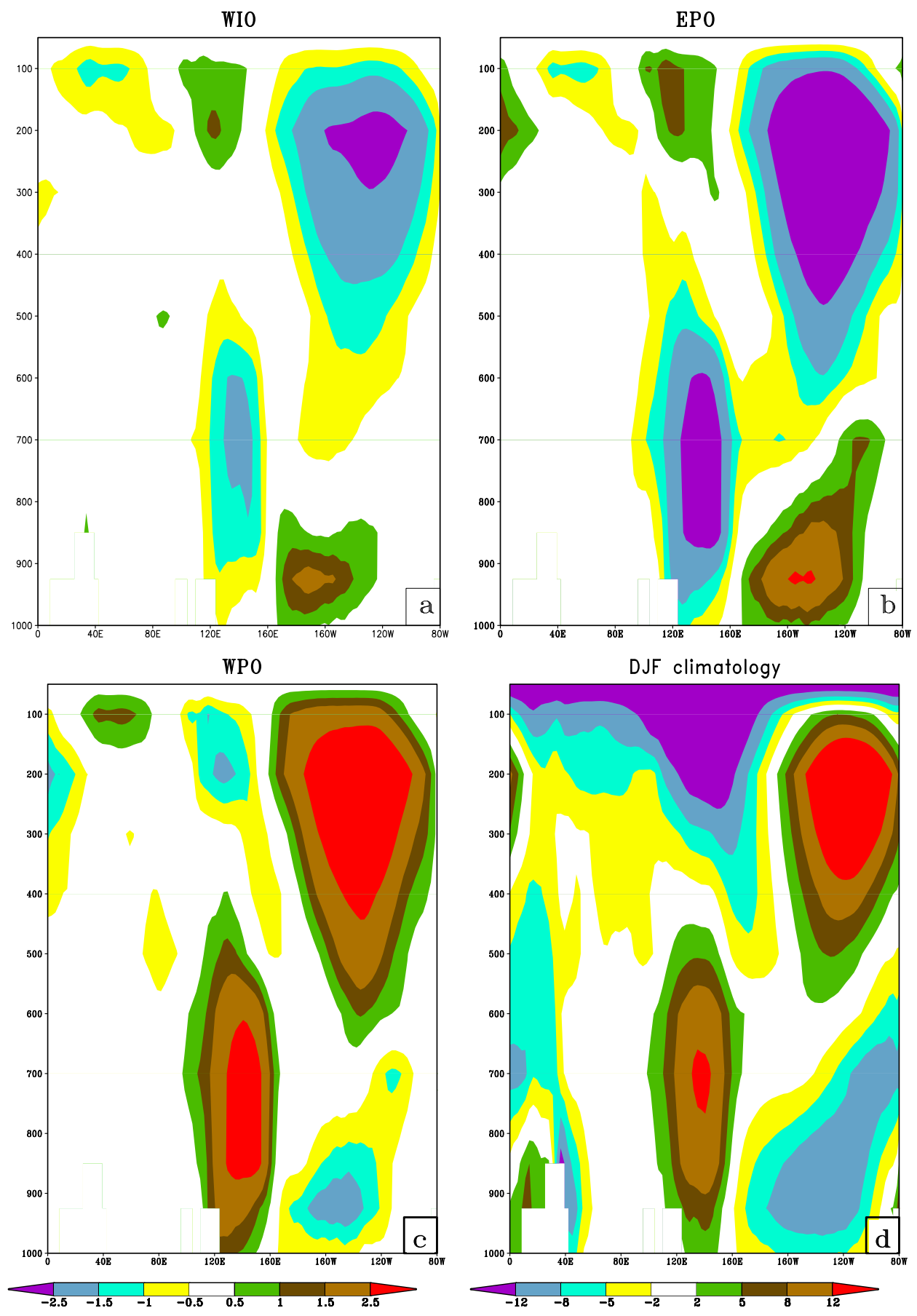

Figure 6: The linear regression of SSTA in a) western Indian Ocean (WIO), b) eastern Pacific Ocean (EPO) and c) western Pacific Ocean (WPO) on control COLA AGCM zonal wind anonmaly along the equator for DJF season. The amplitude of the patterns corresponds to the corresponding standard deviation of the SSTA listed in Table 2. d) The climatological SON equatorial zonal wind cross-section from control COLA AGCM. The units are in $\mathrm{ms}^{-1}$. 

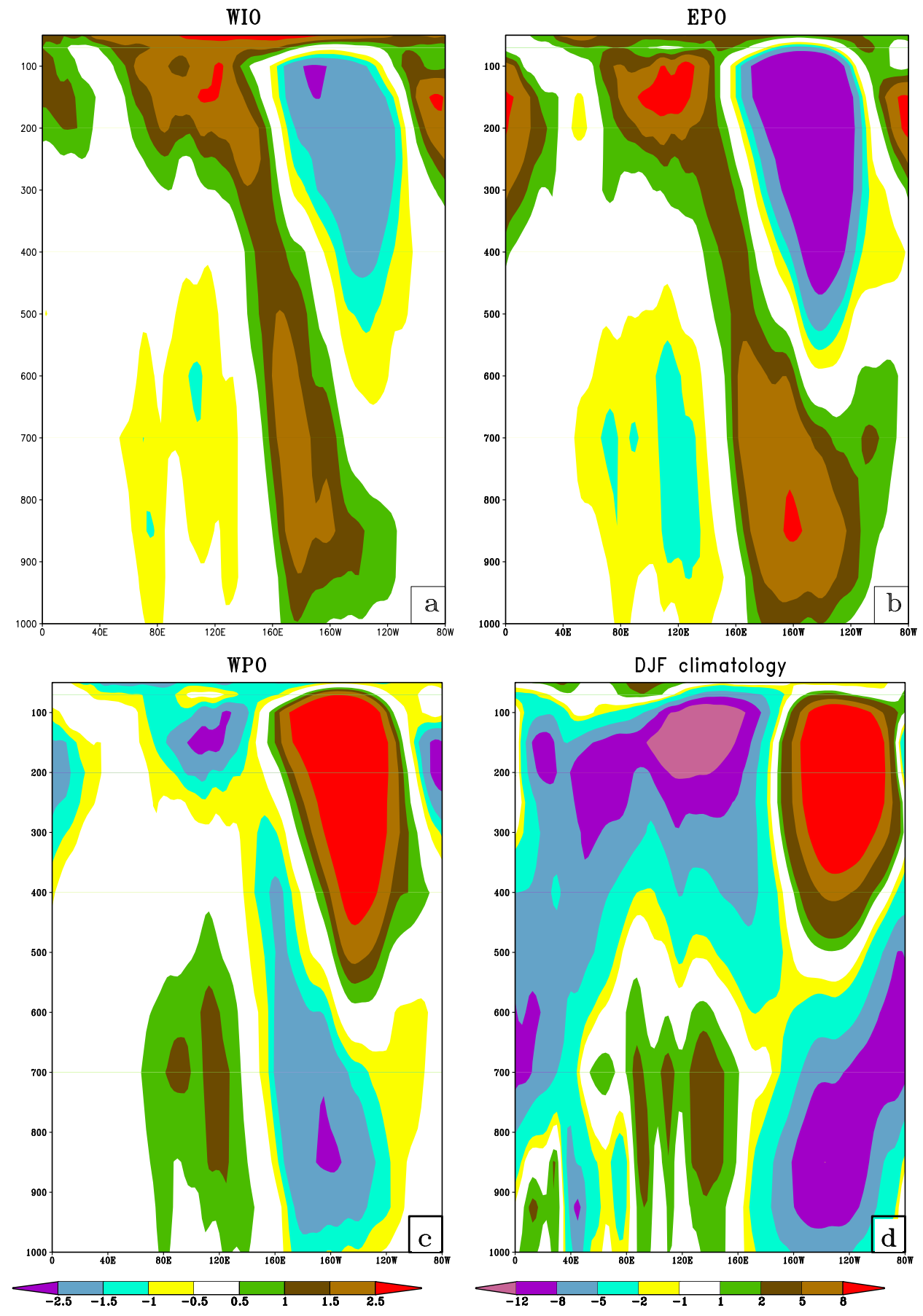

Figure 7: Same as Fig. 6 but the equatorial zonal winds are from NCEP reanalysis. 

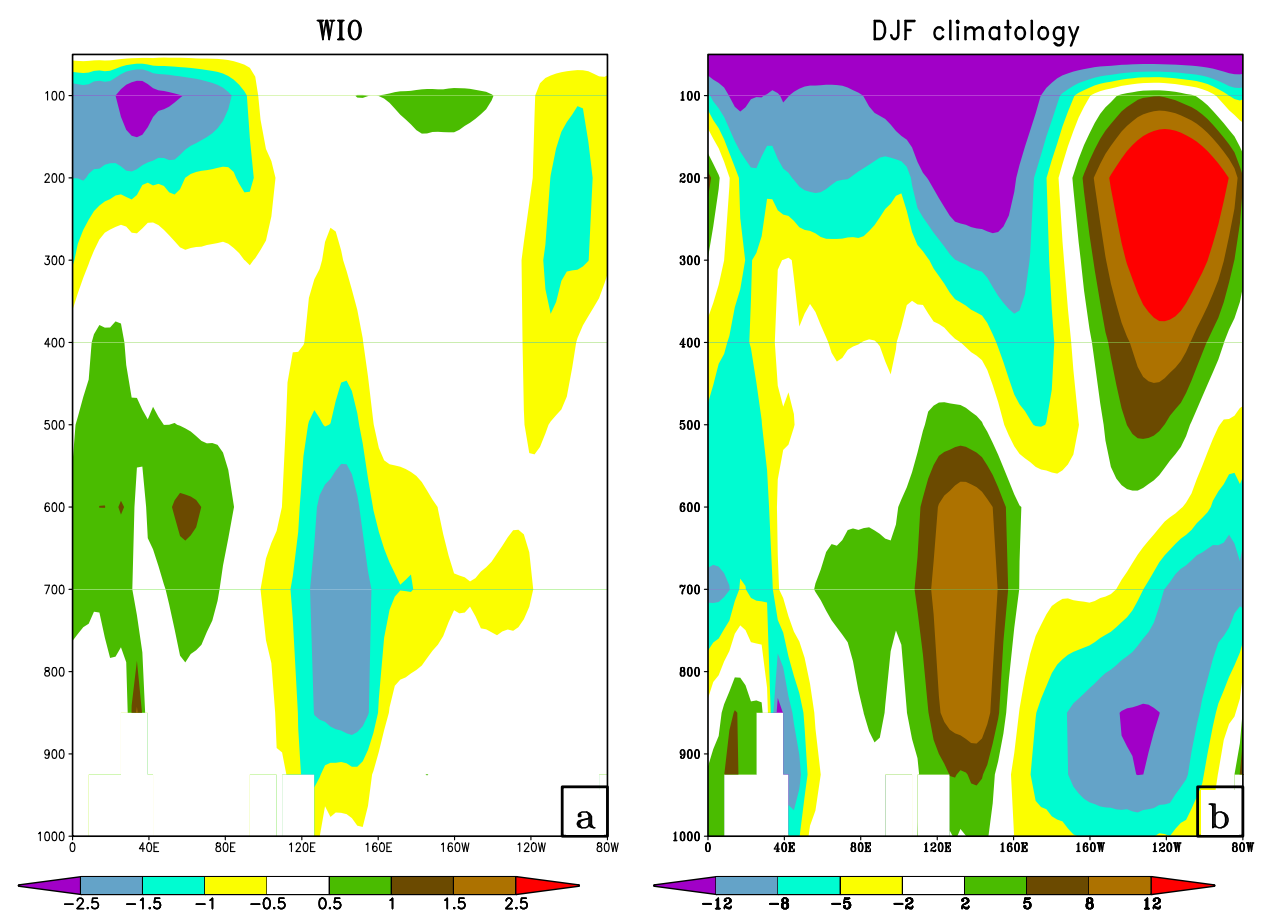

Figure 8: a) The linear regression of SSTA over western Indian Ocean (WIO) on equatorial zonal wind anomaly from the experimental AGCM run for a) DJF season. The amplitude of the patterns corresponds to the standard deviation of the SSTA over western Indian Ocean listed in Table 2. b) The climatological equatorial zonal wind from the experimental runs are shown for DJF season. The units are in $\mathrm{ms}^{-1}$. 